\title{
Retrieval of low-frequency words from mixed lists*
}

\author{
CARL P. DUNCAN \\ Northwestern University, Evanston, Illinois 60201
}

\begin{abstract}
In two experiments Ss were presented either a list of high-or a list of low-frequency words (unmixed lists), or lists containing equal numbers of words from the two frequency levels (mixed lists). In recall there was a significant interaction between level of frequency and type of list: In unmixed lists high-frequency words were better recalled; in mixed lists low-frequency words were better recalled.
\end{abstract}

If Ss are asked to solve anagrams constructed from words of different frequencies in the printed language, solution is easier if the words are of high frequency (Mayzner \& Tresselt, 1958, and many others). It is assumed that this is because Ss tend to think of high-frequency words earlier or in greater numbers. Direct evidence for this appears in studies (e.g., Duncan, 1973) where Ss try to think of words from cues (initial letter, length, etc.). The spew law (Underwood \& Schulz, 1960 ) holds that Ss emit words in order of language frequency.

Suppose $S$ is trying to think of words from a pool containing words of both high- and low-frequency. Are the low-frequency words difficult to retrieve because they are interfered with by the high-frequency words? To attempt to answer this question, it is necessary to control the frequency characteristics of the words in the pool that $S$ is trying to search. To some degree, this can be done by using a one-trial free recall design: $\mathrm{S}$ reads a list of words once, then writes down as many as he can recall in any order. It is known that high-frequency words are recalled better than low-frequency words (e.g., Hall, 1954, and others). However, the interest here is in comparing recall of high- and low-frequency words when they are, or might be, in competition with each other. This requires a design in which words of differing frequency are presented within the same list, i.e., a mixed list design.

\section{EXPERIMENT I}

\begin{abstract}
Method
A list of $24 \mathrm{HF}$ (high-frequency) words was prepared. All had frequencies of 40-100+ per million words in Thorndike and Lorge (1944). A list of 24 LF (low-frequency) words, all with frequencies of 1-2 per million, was also selected. All 24 words within each list were five letters in length. Each of the 24 words within a list began with a different letter. All were nouns. From these lists two mixed lists were prepared by putting together the 12 "odd-lettered" HF words (beginning with a, c, etc.) and the 12 "even-lettered" LF words (b, d, etc.) in one mixed list, and the 12 even-lettered HF words and 12 odd-lettered LF words in the other mixed list. Each word in each list was typed on a $2 \times 2$ in. slide. The 24 words in a list were arranged in two different orders, such that there were no obvious alphabetical
\end{abstract}

\footnotetext{
*Thanks are due Dr. and Mrs. Alan Brown.
}

sequences in either order. These orders were used for presenting the 24 slides in each list. Half the Ss on each list were presented the slides in one order, half in the other order.

The Ss, run in small groups, were told, "I am going to show you a list of words, presented one at a time. The list will consist of 24 five-letter words, each beginning with a different letter of the alphabet, with only $\mathrm{x}$ and $\mathrm{z}$ not being used. Try to learn all the words." Each word appeared on the screen for $2 \mathrm{sec}$. After presentation, S was told, "Write down as many of the words as you can, in any order, remembering that there were words beginning with every letter except $\mathrm{x}$ and $\mathrm{z}$." There were $30 \mathrm{Ss}$ for each of the four lists.

\section{Results}

From the unmixed lists, the mean number of words recalled was 10.90 for HF, 8.93 for LF. Thus, as has been found before, HF words are somewhat better recalled than LF words when one compares lists containing words all of the same frequency. However, from the mixed lists, the mean recall was 9.70 for $\mathrm{HF}$, 11.03 for LF. When the two levels of frequency were mixed within a list, there was a reversal; LF words were recalled better than HF words. (The mixed list results were obtained by combining data from the two mixed lists. The results are the same if each mixed list is separately compared to the unmixed lists.)

Analysis of variance of the four means revealed that neither the main effect of frequency (high or low) nor the main effect of list (mixed or unmixed) was significant; both Fs were less than one. However, the interaction between frequency and list was highly significant $[F(1,116)=8.75, p<.01]$. Thus, HF words were recalled better in a list containing all HF words, but LF words were recalled better when mixed in a list contaning HF words.

\section{EXPERIMENT II}

In Experiment II an attempt was made to direct recall by cueing. The cueing procedure used (see below) was such that in the lists where HF and LF words were mixed, $\mathrm{S}$ was cued toward recalling only the high- or only the low-frequency words. It was thought that this procedure might modify the frequency effect found with mixed lists in Experiment I. 


\section{Method}

The general method was identical to that of Experiment I up to the point of recall. As noted earlier, each word in a list began with a different letter and this was called to S's attention in the instructions prior to learning in both experiments. In Experiment II, immediately after presentation of the last slide, E presented a cue slide containing the 12 odd-numbered letters for half the $\mathrm{Ss}$ in each condition, the 12 even-numbered letters for the remaining Ss. The Ss were told, "Write down the words that began with the 12 letters on this slide-and only those-in any order. This slide will stay on."

For Ss who had been presented an unmixed list (either HF or LF), the cue slides merely directed recall toward one or the other half of a list of words,all of the same frequency. But for Ss in the mixed condition, one of the cue slides directed recall toward the 12 high-, the other toward the 12 low-, frequency words. There were 32 Ss for each of the four lists.

\section{Results}

In Experiment II, the maximum number of words that could be recalled correctly was 12 (vs 24 in Experiment I). For the unmixed lists, mean recall was 6.28 for HF, 5.34 for LF. Thus, the direction is the same as in Experiment I, higher recall of HF in unmixed lists. For the mixed list (again combining data from the two mixed lists), mean recall was 4.69 for HF, 5.44 for LF. As in Experiment I, there is a reversal of the effect of frequency from unmixed to mixed lists. Overall recall was somewhat higher in Experiment II.

Analysis of variance of the four means revealed that neither of the main effects of frequency or list was significant. The Frequency by List interaction yielded $F(1,124)=4.92, p<.05$. The results are the same as in Experiment I, but the effect does not appear to be quite as strong. Nevertheless, it was again found that in unmixed lists HF words were recalled better, while in mixed lists LF words were recalled better.

\section{DISCUSSION}

In problem-solving studies such as anagram solving or thinking of words from cues (e.g., Duncan, 1973), E does not exert any more control over S's retrieval pool of words than that exerted by the stimulus (anagram or letter cues) itself. It seems reasonable to assume that in these cases $S$ searches from a pool made up very heavily of HF words. Thus, $S$ tends largely to spew
(Underwood \& Schulz, 1960) HF words. The number of LF words emitted is very sniall (Duncan, 1973).

It is possible, however, to exert a high (though not perfect) degree of control over the retrieval pool by presenting to $\mathrm{S}$ a specific list of words which he is to retrieve (recall). If the list consists entirely of HF words, S will retrieve some of them, but by no means all that would be correct in the situation. Also, he will spew a few HF words that were not presented (extralist intrusions in recall experiments) or that do not fit the stimulus (wrong responses in problem-solving studies). The level of retrieval, and the correctness of retrieval, of HF words has been essentially the same whether $S$ was presented with a list of such words to recall or with a cueing stimulus such as a letter or an anagram from which to think of words (Duncan, 1973).

In problem-solving experiments, $S$ does not seem to have available a large pool of LF words, so problems requiring such words are hard to solve. If $S$ is provided with such a pool by list presentation, retrieval (recall) of LF words is dramatically improved (over that obtained in problem solving), but not quite to the level reached by HF words (Duncan, 1973). However, if LF words are mixed in equal numbers with HF words in a presented list, both experiments of the present study found somewhat higher recall of the low-than of the high-frequency words.

The question that prompted the present study was whether $\mathrm{HF}$ words interfere with the retrieval of LF words. In largely uncontrolled retrieval pools, as in problem-solving research, this might be true (though it probably is not). But it is not true if LF words are represented in equal numbers in a more controlled (list presentation) pool. In fact, in the mixed list, LF words may have interfered with the recall of HF words. An analysis of order of emission in the mixed lists of Experiment I showed that more HF than LF words were recalled in the first and in the second words recalled (spew was not totally extinguished), but from Position 3 onward more LF than HF words were emitted. Thus, if the relative unavailability of LF words is minimized by list presentation, they may in some cases be retrieved as well or better than $\mathrm{HF}$ words.

\section{REFERENCES}

Duncan, C. P. Storage and retrieval of low-frequency words. Memory \& Cognition, 1973, 1, 129-132.

Hall, J. F. Learning as a function of word-frequency. American Journal of Psychology, 1954, 67, 138-140.

Mayzner, M. H., \& Tresselt, M. E. Anagram solution times: A function of letter order and word frequency. Journal of Experim ental Psychology, 1958, 56, 376-379.

Thorndike, E. L., \& Lorge, I. The teacher's word book of 30,000 words. New York: Teachers College, Columbia University Press, 1944.

Underwood, B. J., \& Schulz, R. W. Meaningfulness and verbal learning. Philadephia: Lippincott, 1960.

(Received for publication June 17, 1974.) 